RESEARCH

\title{
Safety and efficacy of two starting doses of vandetanib in advanced medullary thyroid cancer
}

\author{
Mimi I Hu1, Rossella Elisei², Marek Dedecjus ${ }^{3}$, Aron Popovtzer ${ }^{4}$, Maralyn Druce ${ }^{5}$, Ellen Kapiteijn ${ }^{6}$, Furio Pacini7, \\ Laura Locati ${ }^{8}$, Jolanta Krajewska9 ${ }^{\text {, Richard Weiss }}{ }^{10}$ and Robert F Gagel1 \\ 'Department of Endocrine Neoplasia and Hormonal Disorders, University of Texas MD Anderson Cancer Center, Houston, Texas, USA \\ 2Department of Clinical and Experimental Medicine, University of Pisa, Pisa, Italy \\ ${ }^{3} \mathrm{M}$. Sklodowska-Curie Memorial Cancer Center and Institute of Oncology, Warsaw, Poland \\ 4Davidoff Cancer Center, Tel-Aviv University, Petah Tikva, Israel \\ ${ }^{5}$ William Harvey Research Institute, Barts and the London School of Medicine and Dentistry, London, UK \\ ${ }^{6}$ Leiden University Medical Center, Leiden, The Netherlands \\ 7Thyroid Unit, University of Siena, Siena, Italy \\ ${ }^{8} \mathrm{Head}$ and Neck Medical Oncology Department, Fondazione IRCCS Istituto Nazionale dei Tumori, Milan, Italy \\ ${ }^{9} \mathrm{M}$. Sklodowska-Curie Memorial Institute Cancer Center, Gliwice Branch, Gliwice, Poland \\ 10Sanofi Genzyme, Cambridge, Massachusetts, USA
}

Correspondence should be addressed to M I Hu: mhu@mdanderson.org

\begin{abstract}
Vandetanib is an oral tyrosine kinase inhibitor approved for treatment of advanced symptomatic or progressive medullary thyroid cancer (MTC). The current study (NCT01496313) evaluated the benefit-risk of two starting doses of vandetanib in patients with symptomatic or progressive MTC. Patients were randomized 1:1 to receive vandetanib 150 or $300 \mathrm{mg}$ daily and followed for a maximum of 14 months (Part A), with the option to then enter an open-label phase (Part B) investigating vandetanib 100, 150, 200 and $300 \mathrm{mg}$ daily doses. Efficacy was assessed in Part A, and safety and tolerability during Parts $A$ and $B$ up to 2 years post randomization. Eighty-one patients were randomized in Part A and 61 patients entered Part B, of whom 37 (60.7\%) received 2 years of treatment. Overall, $25 \%$ of patients experienced an objective response (OR) at 14 months (OR rate, $0.29(95 \% \mathrm{Cl}, 0.176-0.445)$ for $300 \mathrm{mg}$, and $0.20(95 \% \mathrm{Cl}, 0.105-0.348)$ for $150 \mathrm{mg}$; one-sided $P$ value approximately 0.43 ). The most common adverse events (AEs) included diarrhea, hypocalcemia, asthenia, QTc prolongation, hypokalemia and keratopathy, all at generally higher incidence with 300 vs $150 \mathrm{mg}$ (Part A). Part B safety and tolerability was consistent with Part A. OR was observed with both vandetanib doses; the $300 \mathrm{mg}$ dose showed a more favorable trend vs $150 \mathrm{mg}$ as initial dose. Thus, for most patients, $300 \mathrm{mg}$ vandetanib is the most appropriate starting dose; dose reductions to manage AEs and lower initial doses for patients with particular comorbidities can be considered.
\end{abstract}

\author{
Key Words \\ - vandetanib \\ - medullary thyroid cancer \\ - safety \\ - efficacy
}

C) 2019 Society for Endocrinology Published by Bioscientifica Ltd. Printed in Great Britain
Endocrine-Related Cancer (2019) 26, 241-250 


\section{Introduction}

Medullary thyroid cancer (MTC) is a malignancy of the parafollicular C cells of the thyroid gland, accounts for an estimated $1-2 \%$ of all thyroid cancers, and is either hereditary (in 25\% of patients) or sporadic (Wells Jr et al. 2015). If treated early, 10 -year survival is $70-80 \%$, but this decreases to $40 \%$ or lower for patients with locally advanced or metastatic disease, with a median overall survival of 2-3 years in these patients (Modigliani et al. 1998, Roman et al. 2006, Kloos et al. 2009). Progress in identifying the key genetic alterations and dysregulated signaling pathways involved in MTC have led to the development of targeted therapies for this disease (Martins et al. 2006, Wells Jr et al. 2015).

Vandetanib (Caprelsa) is a once-daily, oral tyrosine kinase inhibitor that selectively targets rearranged during transformation (RET) receptor, vascular endothelial growth factor receptor and epidermal growth factor receptor signaling (Carlomagno et al. 2002, Wedge et al. 2002, Wells et al. 2010). In the Phase III ZETA clinical trial in patients with locally advanced or metastatic hereditary MTC (Wells et al. 2012), median progression-free survival was significantly prolonged from 19.3 months with placebo to a predicted 30.5 months (median not yet reached at data cut-off) with vandetanib (hazard ratio, 0.46; $P<0.0001$ ) (Wells et al. 2012). Based on these results, the US Food and Drug Administration (FDA) approved vandetanib for the treatment of symptomatic or progressive MTC in patients with unresectable locally advanced or metastatic disease in 2011.

A key issue relating to the use of vandetanib is whether the Phase III study identified the correct dose of vandetanib given several unexplained deaths in the vandetanib treatment group. To address this concern and to help inform decision-making on vandetanib starting doses, this study was designed to identify the objective response rates (ORR) and evaluate the safety and tolerability of two starting doses of vandetanib (150 and $300 \mathrm{mg}$ ) in patients with symptomatic or progressive MTC.

\section{Materials and methods}

\section{Patients}

Eligible patients were adults aged $\geq 18$ years with histologically confirmed, unresectable, locally advanced or metastatic, hereditary or sporadic MTC. Patients were required to have objective disease progression (within 14 months of randomization) and/or one or more symptoms related to the patient's MTC (investigator assessed). Other key inclusion and exclusion criteria are detailed in the Supplementary data (see section on supplementary data given at the end of this article).

\section{Study design and treatment}

This study was an international, randomized, doubleblind study (NCT01496313) in two parts: double-blind and randomized Part A and open-label Part B. In Part A, patients were randomized 1:1 to receive once-daily oral vandetanib at either 150 or $300 \mathrm{mg}$ and followed for a maximum of 14 months. The $150 \mathrm{mg}$ dose was produced for clinical trial purposes only. Patients who received blinded treatment for 14 months after randomization were eligible to enter Part B. A more detailed description of the study design can be found in the Supplementary data.

All patients provided written informed consent. The protocol was approved by all relevant institutional ethical committees or review bodies (full details provided in the Supplementary data), and the study was conducted in accordance with the Declaration of Helsinki and Good Clinical Practice.

\section{Objectives}

The primary objective was to assess the ORR for the two vandetanib starting doses (150 and $300 \mathrm{mg}$ ) in patients with unresectable locally advanced or metastatic MTC with progressive or symptomatic disease. Secondary objectives included best percentage change in target lesion size during Part A, pharmacokinetics (PK) in Part A and safety and tolerability during Parts A and B.

\section{Assessments}

\section{Efficacy: Part A}

OR (defined as complete response (CR) and partial response (PR)) was based on objective tumor measurements performed at screening, and then every 12 weeks until progression, or up to 14 months on randomized treatment, whichever came first. Patients who discontinued vandetanib prior to objective progression or 14 months on randomized treatment continued to have tumor assessments performed until objective progression. Tumor assessments were categorized based on Response Evaluation Criteria in Solid Tumors (RECIST) version 1.1, with additional confirmatory scans performed $\geq 4$ weeks and $\leq 12$ weeks following the date of first response. 


\section{Safety: Parts A and B}

Safety was assessed throughout the study (Parts A and B) by monitoring and recording adverse events (AEs) by Common Terminology Criteria for Adverse Events v4.0, vital signs, laboratory data, electrocardiogram (ECG) parameters and echocardiograms, ophthalmological evaluation and physical examination. A QTcF prolongation was defined as QTc interval $>450 \mathrm{~ms}$. Prolongations with QTcF $>480$ and $>500 \mathrm{~ms}$ were also summarized. QTcF was summarized both as a continuous variable, using the observed values, and as a categorical variable, using the categories $\leq 500$ and $>500 \mathrm{~ms}$. If a patient's dose was reduced for an $\mathrm{AE}$ or $\mathrm{QT}$ prolongation, the investigator had the option to continue the patient on the reduced dose (vandetanib $100 \mathrm{mg}$ for patients randomized to $150 \mathrm{mg}$, or $200 \mathrm{mg}$ for patients randomized to $300 \mathrm{mg}$ ) in Part B if the patient was assessed as receiving benefit from vandetanib.

\section{Statistical methods}

A sample size of 40 patients per arm (80 in total) would allow the ORR in each treatment arm to be estimated with adequate precision. For example, if $8 / 40$ patients respond, the ORR would be $20 \%$. The corresponding 95\% CI using the Wilson score method would be (10.5-34.8\%), which lies entirely to the right of zero, thus providing evidence that the ORR for this treatment group was likely to be greater than zero. The proposed sample size for this study was therefore 80 patients in total, with 40 patients to be randomized in each treatment group. As the aim of the study was to provide additional information on the likely range of response rates with a starting dose of either $150 \mathrm{mg}$ or $300 \mathrm{mg}$, there was no formal hypothesis testing to compare the ORR between the two treatment groups.

Relative dose intensity (RDI) was calculated as the ratio of the total vandetanib dose received over the total exposure period, in $\mathrm{mg}$, divided by the total number of days from the beginning of treatment to the day of discontinuation or data cut-off date multiplied by $100 \%$ (this analysis was only conducted for Part A).

The efficacy population (Part A) included all randomized patients regardless of the treatment received. The per protocol (PP) population included all patients who received at least one dose of randomized treatment and who had at least two follow-up RECIST assessments while on treatment. The safety population included all patients who received at least one dose of treatment. Additional information is provided in the Supplementary data.

\section{Results}

\section{Patients}

A total of 81 patients were randomized in Part A. Of these, 61 (87.5\% of patients in the $150 \mathrm{mg}$ group, $63.4 \%$ of patients in the $300 \mathrm{mg}$ group) completed Part A, entered Part B and received open-label vandetanib (Fig. 1). Twenty patients discontinued treatment in Part A $(12.5 \%$ in the $150 \mathrm{mg}$ group and $36.6 \%$ in the $300 \mathrm{mg}$ group); the main reason for discontinuation was AEs (Fig. 1). Of the 61 patients who entered Part B, 37 (60.7\%) received a total of 2 years of treatment and 24 (39.3\%) discontinued treatment in Part B prior to 2 years, most commonly as a result of worsening of the condition under investigation (14 (23.0\%) patients; Fig. 1). All 81 randomized patients received treatment and were included in the efficacy and safety populations; 65 patients were included in the PP population.

Patient characteristics and baseline demographics were similar in both arms (Table 1). The mean age of patients was 52.5 years, with over half (51.9\%) aged $\geq 40$ to $<65$ years. Most patients presented with sporadic disease (71.6\%) and had metastatic disease (61.7\%).

\section{Efficacy: Part A}

Of the 81 patients analyzed for efficacy, $24.7 \%$ experienced an OR at 14 months: 19 patients had an objective PR and 1 patient had a CR (Table 2). There were more responders in the $300 \mathrm{mg}$ group (ORR, 29.3\%; 95\% CI, $17.6-44.5 \%)$ than in the $150 \mathrm{mg}$ group (ORR, 20.0\%; 95\% CI, $10.5-34.8 \%$; $P$-value approximately 0.43 for one-sided comparison); duration of response and time to onset were similar between groups (Table 2). Primary analysis of ORR was also determined for the PP population and showed greater improvements than for the efficacy population: $30.8 \%$ of patients experienced an objective response by 14 months (23.5\% receiving $150 \mathrm{mg}$ and $38.7 \%$ receiving $300 \mathrm{mg}$ (Table 2)). Of the patients who did not respond, a smaller proportion in the $300 \mathrm{mg}$ group (4.9\%) had disease progression than in the $150 \mathrm{mg}$ group (22.5\%) (Table 2).

At baseline, the mean target lesion size was bigger in the $300 \mathrm{mg}$ group $(76.6 \mathrm{~mm})$ compared with the $150 \mathrm{mg}$ group $(60.1 \mathrm{~mm})$. Most patients had a reduction in target lesion size, with more reductions observed with $300 \mathrm{mg}$ compared with $150 \mathrm{mg}$ (Supplementary Fig. 1).

\section{Safety: Parts A and B}

Median duration of treatment in randomized Part A was 11.8 months with $150 \mathrm{mg}$ and 13.7 months with $300 \mathrm{mg}$. 


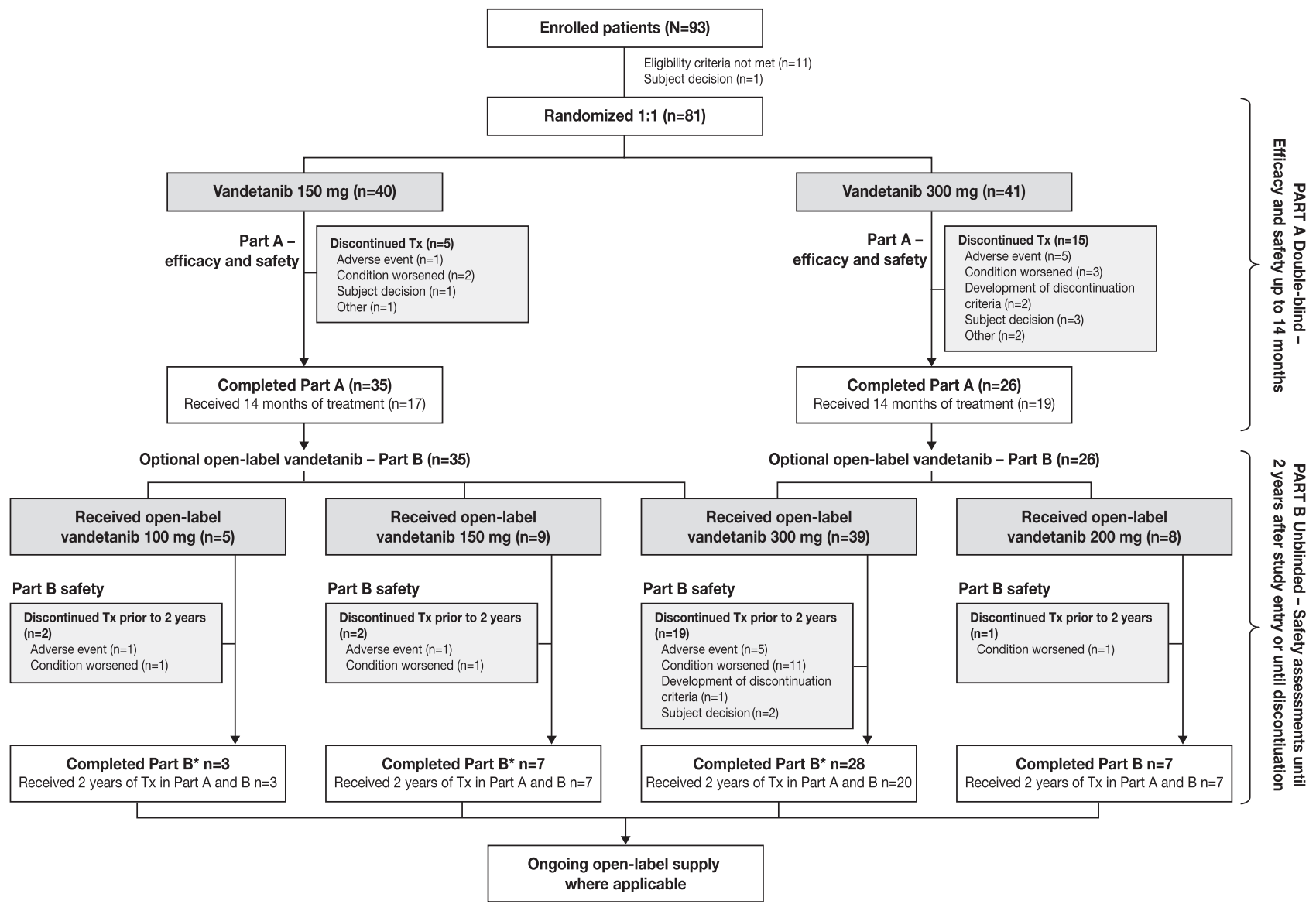

Figure 1

Patient disposition.

In Part $\mathrm{A}$ in the 150 and $300 \mathrm{mg}$ groups, dose reductions were required by $6(15 \%)$ and 12 (29\%) patients, respectively (all because of AEs), and dose interruptions were required by 18 (45\%) and 15 (37\%) patients, respectively (the primary reason was AEs (16.0\%)).

RDI was calculated for each dose cohort in Part A as the percentage of the actual dose intensity delivered relative to the intended dose intensity through treatment discontinuation. The mean RDI for the $150 \mathrm{mg}$ and $300 \mathrm{mg}$ dose groups were 93.1 and $91.4 \%$, respectively, indicating that the majority of patients in each group received close to the full expected dose intensity over the course of their treatment in Part A.

Seven patients in Part A (two in the $150 \mathrm{mg}$ group, five in the $300 \mathrm{mg}$ group) and seven patients in Part B (one each in the 100 and $150 \mathrm{mg}$ groups, five in the $300 \mathrm{mg}$ group (four of whom were initially randomized to $150 \mathrm{mg}$ )) reported an AE leading to discontinuation of vandetanib (Table 3). Three of the AEs leading to discontinuation were considered to be causally related to vandetanib in Part A: one event each of angina pectoris (150 mg group), peripheral motor neuropathy and cholecystitis (both in the $300 \mathrm{mg}$ group). In Part B, one AE of QT prolongation on ECG leading to discontinuation was considered to be causally related to vandetanib; this patient was initially randomized to $150 \mathrm{mg}$ but received $100 \mathrm{mg}$ in Part B.

In Part A, the most frequently reported AEs in the vandetanib $150 \mathrm{mg}$ group were diarrhea (37.5\%), increased blood thyroid-stimulating hormone (27.5\%), rash (20.0\%), hypocalcemia (20.0\%), hypertension $(20.0 \%)$ and fatigue (20.0\%); the most frequently reported AEs in the $300 \mathrm{mg}$ group were diarrhea (43.9\%), QT prolongation on ECG (34.1\%), rash (31.7\%), keratopathy (31.7\%), hypocalcemia (29.3\%), hypertension (26.8\%) and increased blood thyroid-stimulating hormone (22.0\%; Table 4). Generally, the incidence of AEs was similar between treatment groups in Part A, although prolonged QT on ECG was reported in a higher proportion of patients receiving $300 \mathrm{mg}$ than in the $150 \mathrm{mg}$ group (14 vs 5 patients (34.1 vs $12.5 \%$ )). Grade $\geq 3$ AEs occurred in $21(51.2 \%)$ and 17 (42.5\%) patients receiving $300 \mathrm{mg}$ and $150 \mathrm{mg}$, respectively in Part A. The most common AEs of grade $\geq 3$ were hypertension https://erc.bioscientifica.com https://doi.org/10.1530/ERC-18-0258
(C) 2019 Society for Endocrinology Published by Bioscientifica Ltd. Printed in Great Britain 
Table 1 Patient demographics and baseline clinical characteristics (full population).

\begin{tabular}{l}
\hline \\
Sex, $n$ (\%) \\
Male \\
Female \\
Mean age (years) \\
Age group, $n$ (\%) \\
$\geq 18$ to $<40$ years \\
$\geq 40$ to $<65$ years \\
$\geq 65$ to $<75$ years \\
$\geq 75$ years \\
Race, $n$ (\%) \\
White \\
Black or African American \\
Asian \\
Other \\
Ethnic group, $n$ (\%) \\
Non-Hispanic or Latino \\
Hispanic or Latino \\
WHO performance status \\
0 \\
1 \\
2
\end{tabular}

\begin{tabular}{|c|c|c|}
\hline \multicolumn{2}{|c|}{ Vandetanib } & \multirow[b]{2}{*}{ Total $(n=81)$} \\
\hline $150 \mathrm{mg}(n=40)$ & $300 \mathrm{mg}(n=41)$ & \\
\hline 25 (62.5) & $29(70.7)$ & $54(66.7)$ \\
\hline 15 (37.5) & 12 (29.3) & 27 (33.3) \\
\hline 52.2 & 52.7 & 52.5 \\
\hline $9(22.5)$ & $9(22.0)$ & $18(22.2)$ \\
\hline $22(55.0)$ & $20(48.8)$ & 42 (51.9) \\
\hline 7 (17.5) & $10(24.4)$ & $17(21.0)$ \\
\hline $2(5.0)$ & $2(4.9)$ & $4(4.9)$ \\
\hline 39 (97.5) & 37 (90.2) & 76 (93.8) \\
\hline 0 & $1(2.4)$ & $1(1.2)$ \\
\hline $1(2.5)$ & $2(4.9)$ & $3(3.7)$ \\
\hline 0 & $1(2.4)$ & $1(1.2)$ \\
\hline 39 (97.5) & $41(100)$ & $80(98.8)$ \\
\hline $1(2.5)$ & 0 & $1(1.2)$ \\
\hline 28 (70.0) & $23(56.1)$ & $51(63.0)$ \\
\hline 12 (30.0) & 17 (41.5) & 29 (35.8) \\
\hline $0(0.0)$ & $1(2.4)$ & $1(1.2)$ \\
\hline $3(7.5)$ & $4(9.8)$ & $7(8.6)$ \\
\hline 32 (80.0) & $26(63.4)$ & 58 (71.6) \\
\hline 5 (12.5) & $11(26.8)$ & 16 (19.8) \\
\hline $6(15.0)$ & $7(17.1)$ & $13(16.0)$ \\
\hline 7 (17.5) & $10(24.4)$ & $17(21.0)$ \\
\hline 7 (17.5) & $3(7.3)$ & 10 (12.3) \\
\hline $1(2.5)$ & 0 & $1(1.2)$ \\
\hline $1(2.5)$ & 0 & $1(1.2)$ \\
\hline $34(85.0)$ & 34 (82.9) & $68(84.0)$ \\
\hline $6(15.0)$ & $7(17.1)$ & 13 (16.3) \\
\hline 37 (92.5) & 40 (97.6) & 77 (95.1) \\
\hline $65.0(7-445)$ & $58.5(3-420)$ & $65.0(3-445)$ \\
\hline
\end{tabular}

MTC, medullary thyroid cancer; WHO, World Health Organization.

(8 (9.9\%) patients; 5 receiving $300 \mathrm{mg}, 3$ receiving $150 \mathrm{mg}$ ) and dermatitis acneiform (3 (3.7\%) patients; all received $150 \mathrm{mg})$.

In open-label Part B, 10 AEs were reported in $>10 \%$ of patients in total (Table 4). The most common AE was diarrhea, which was reported in 13 (21.3\%) patients (Table 4). A total of 20 (32.8\%) patients reported a grade $\geq 3$ AE. In most cases, grade $\geq 3$ AEs were reported in no more than one patient in total, except for hypocalcemia and asthenia (both $n=3,4.9 \%$ ), hypertension, hyponatremia, diarrhea and QT prolongation on ECG (all $n=2,3.3 \%$ ).

No serious AEs (SAEs) occurred in more than one patient during Part A or B, with the exception of hypocalcemia, which was reported by two patients (one patient receiving $200 \mathrm{mg}$, one patient receiving
$300 \mathrm{mg}$ ). In Part A, 10 SAEs in seven patients were considered treatment related (four events in three patients receiving $150 \mathrm{mg}$, six events in four patients receiving $300 \mathrm{mg}$ ). In Part B, four SAEs in three patients were considered treatment related (general physical health deterioration in a patient receiving $200 \mathrm{mg}$, hypocalcemia and colitis in a patient receiving $300 \mathrm{mg}$ and post-procedural fistula in a patient receiving $300 \mathrm{mg}$ ).

During Parts A and B, five and eight patients, respectively, died. None of these deaths were considered related to vandetanib. Further details are described in the Supplementary data.

In Part A, ophthalmology results showed a slow increase in eye conditions over time, with slightly higher prevalence (c) 2019 Society for Endocrinology Published by Bioscientifica Ltd. Printed in Great Britain 
Table 2 Summary of efficacy results.

\begin{tabular}{|c|c|c|c|}
\hline & \multicolumn{2}{|c|}{ Vandetanib } & \multirow[b]{2}{*}{ Total $(n=81)$} \\
\hline & $150 \mathrm{mg}(n=40)$ & $300 \mathrm{mg}(n=41)$ & \\
\hline \multicolumn{4}{|l|}{ Primary efficacy analysis } \\
\hline Efficacy population, $n$ & 40 & 41 & 81 \\
\hline ORR $(\mathrm{Cl})$ & $20.0 \%(10.5-34.8 \%)$ & $29.3 \%(17.6-44.5 \%)$ & $24.7 \%(16.6-35.1 \%)$ \\
\hline PP population, $n$ & 34 & 31 & 65 \\
\hline ORR $(\mathrm{Cl})$ & $23.5 \%(12.4-40.0 \%)$ & $38.7 \%(23.7-56.2 \%)$ & $30.8 \%(20.9-42.8 \%)$ \\
\hline \multicolumn{4}{|l|}{ Best objective response, $n(\%)$} \\
\hline \multicolumn{4}{|l|}{ Response } \\
\hline Total & $8(20.0)$ & $12(29.3)$ & $20(24.7)$ \\
\hline CR & 0 & $1(2.4)$ & $1(1.2)$ \\
\hline PR & $8(20.0)$ & $11(26.8)$ & $19(23.5)$ \\
\hline \multicolumn{4}{|l|}{ Non-response } \\
\hline Total & $32(80.0)$ & $29(70.7)$ & $61(75.3)$ \\
\hline Stable disease & $21(52.5)$ & $23(56.1)$ & $44(54.3)$ \\
\hline Progressive disease & $9(22.5)$ & $2(4.9)$ & 11 (13.6) \\
\hline \multirow[t]{3}{*}{ Non-evaluable } & $2(5.0)$ & $4(9.8)$ & $6(7.4)$ \\
\hline & \multicolumn{2}{|c|}{ Vandetanib } & \\
\hline & $150 \mathrm{mg}(n=8)$ & $300 \mathrm{mg}(n=12)$ & Total $(n=20)$ \\
\hline Median duration of response (months) $(95 \% \mathrm{Cl})$ & $9.8(2.8,11.2)$ & $8.4(3.0,11.2)$ & $8.4(3.0,11.2)$ \\
\hline Median onset of response (months) $(95 \% \mathrm{Cl})$ & $4.2(2.8,11.2)$ & $4.4(2.8,11.1)$ & $4.3(2.8,11.1)$ \\
\hline
\end{tabular}

Results are for the efficacy population unless otherwise stated. The confirmed ORR was defined as the percentage of patients with a best response of CR or PR according to RECIST version 1.1 at the end of the 14-month blinded phase (Part A) or before progression, whichever came first. The best objective response was derived from the post-baseline assessments of objective tumor response within 14 months after randomization using the hierarchy $\mathrm{CR}>\mathrm{PR}>$ stable disease $>$ progressive disease $>$ non-evaluable.

$\mathrm{Cl}$, confidence interval; $\mathrm{CR}$, complete response; ORR, objective response rate; PP, per protocol; PR, partial response.

of vortex keratopathy and cornea epithelium in the $300 \mathrm{mg}$ group compared with the $150 \mathrm{mg}$ group, although there was no visual compromise. In Part $\mathrm{B}$, the incidence of vortex keratopathy increased slightly from baseline; however, the incidence of cornea epithelium and cornea stroma abnormalities remained stable throughout the dosing groups.

In Part A, four (4.9\%) patients had QTcF >500 ms (three patients receiving $300 \mathrm{mg}$, one patient receiving 150 mg; Table 5). In Part B, no patients had QTcF >500 ms

Table 3 Summary of adverse events in any category for Part A (randomized, double-blind phase) and Part B (open-label phase): safety population.

\begin{tabular}{|c|c|c|c|c|c|c|c|c|}
\hline \multirow[b]{3}{*}{ Patients, $\boldsymbol{n}(\%)^{*}$} & \multicolumn{3}{|c|}{ Part A (randomized, double blind) } & \multicolumn{5}{|c|}{ Part B (open label) } \\
\hline & \multicolumn{2}{|c|}{ Vandetanib } & \multirow[b]{2}{*}{$\begin{array}{l}\text { Total } \\
(n=81)\end{array}$} & \multicolumn{4}{|c|}{ Vandetanib } & \multirow[b]{2}{*}{$\begin{array}{l}\text { Total } \\
(n=61)\end{array}$} \\
\hline & $\begin{array}{l}150 \mathrm{mg} \\
(n=40)\end{array}$ & $\begin{array}{l}300 \mathrm{mg} \\
(n=41)\end{array}$ & & $\begin{array}{c}100 \mathrm{mg} \\
(n=5)\end{array}$ & $\begin{array}{l}150 \mathrm{mg} \\
(n=9)\end{array}$ & $\begin{array}{c}200 \mathrm{mg} \\
(n=8)\end{array}$ & $\begin{array}{l}300 \mathrm{mg} \\
(n=39)\end{array}$ & \\
\hline Any $A E$ & 39 (97.5) & $40(97.6)$ & 79 (97.5) & $5(100)$ & $7(77.8)$ & $8(100)$ & 34 (87.2) & $54(88.5)$ \\
\hline$A E$ of grade $\geq 3$ & $17(42.5)$ & $21(51.2)$ & 38 (46.9) & $1(20.0)$ & $1(11.1)$ & $2(25.0)$ & $16(41.0)$ & $20(32.8)$ \\
\hline $\begin{array}{l}\text { AE of grade } \geq 3 \text { causally related } \\
\text { to vandetanib }\end{array}$ & $11(27.5)$ & $12(29.3)$ & $23(28.4)$ & $1(20.0)$ & 0 & $2(25.0)$ & $3(7.7)$ & $6(9.8)$ \\
\hline Any $A E$ with outcome of death & 0 & $2(4.9)$ & $2(2.5)$ & 0 & 0 & 0 & $2(5.1)$ & $2(3.3)$ \\
\hline $\begin{array}{l}\text { Any } A E \text { with outcome of death } \\
\text { causally related to vandetanib }\end{array}$ & 0 & 0 & 0 & 0 & 0 & 0 & 0 & 0 \\
\hline Any $\mathrm{SAE}^{\dagger}$ & $8(20.0)$ & $9(22.0)$ & $17(21.0)$ & 0 & $1(11.1)$ & $1(12.5)$ & $10(25.6)$ & $12(19.7)$ \\
\hline $\begin{array}{l}\text { Any SAE causally related to } \\
\text { vandetanib }^{\dagger}\end{array}$ & $3(7.5)$ & $4(9.8)$ & $7(8.6)$ & 0 & 0 & $1(12.5)$ & $2(5.1)$ & 3 (4.9) \\
\hline $\begin{array}{l}\text { AE leading to treatment } \\
\text { discontinuation }\end{array}$ & $2(5.0)$ & $5(12.2)$ & $7(8.6)$ & $1(20.0)$ & $1(11.1)$ & 0 & $5(12.8)$ & $7(11.5)$ \\
\hline $\begin{array}{l}\text { AE leading to treatment } \\
\text { discontinuation causally } \\
\text { related to vandetanib }\end{array}$ & $1(2.5)$ & $2(4.9)$ & $3(3.7)$ & $1(20.0)$ & 0 & 0 & 0 & $1(1.6)$ \\
\hline
\end{tabular}

*Patients with multiple events in the same category were counted only in that category; tincluding events with outcome of death. $A E$, adverse event; $S A E$, serious adverse event. 
across any vandetanib dose groups; five (12.8\%) patients (all receiving $300 \mathrm{mg}$ ) had QTcF prolongations $>480 \mathrm{~ms}$. In Parts A and B, QTcF prolongations ( $>450 \mathrm{~ms}$ ) occurred sooner and more frequently in the $300 \mathrm{mg}$ group, but there were no reports of torsades de pointes (Table 5).

Pharmacokinetic data for Part A are provided in the Supplementary data.

\section{Discussion}

Patients with advanced or metastatic MTC have a poor prognosis, with chemotherapy and radiation therapy being largely ineffective (Hundahl et al. 1998, Modigliani et al. 1998, Roman et al. 2006). Increased understanding of the molecular pathogenesis of MTC has resulted in the development of targeted therapies and represents an important advance for clinical management of this disease. In 2011, the US FDA approved vandetanib for the treatment of symptomatic or progressive MTC in patients with unresectable locally advanced or metastatic disease. In the EU, vandetanib was approved by the EMA in 2012, for the treatment of aggressive and symptomatic MTC in patients with unresectable locally advanced or metastatic disease. Assessment of the benefit-risk relationship of different vandetanib starting doses has not previously been performed. This may be especially important for populations that are less able to tolerate treatment-related side effects, particularly given the potential for long-term vandetanib treatment. We therefore set out to investigate the safety and efficacy of two vandetanib starting doses, 150 and $300 \mathrm{mg}$, in patients with unresectable locally advanced or metastatic MTC with progressive or symptomatic disease.

Overall, 25\% of patients experienced an objective response in the first 14 months of treatment, with more responders in the vandetanib $300 \mathrm{mg}$ group compared with the $150 \mathrm{mg}$ group (ORR, 29 vs 20\%). Duration of response and time to onset of response were similar between treatment groups, although it should be noted that the duration results were heavily censored at the last RECIST visit. Progressive disease was observed in $22.5 \%$ of patients in the vandetanib $150 \mathrm{mg}$ group and in $4.9 \%$ of patients in the $300 \mathrm{mg}$ group. Although the confidence intervals overlapped, our findings suggest a trend toward a better response for $300 \mathrm{mg}$ vs the $150 \mathrm{mg}$ dose. PK data showed that clearance was similar after dosing at 150 and $300 \mathrm{mg}$, with steady-state exposure approximately two-fold higher with the $300 \mathrm{mg}$ dose than with the $150 \mathrm{mg}$ dose.

Safety and tolerability assessments were conducted in Parts A and B. Overall, vandetanib was well tolerated; the rate of discontinuation due to toxicity was low and,

Table 4 Common adverse events (frequency $\geq 15 \%$ in any treatment group for Part A or $>10 \%$ for total treatment group in Part B) for Part A (randomized, double-blind phase) and Part B (open-label phase): safety population.

\begin{tabular}{|c|c|c|c|c|c|c|c|c|}
\hline \multirow[b]{3}{*}{ Patients, $\boldsymbol{n}(\%)$} & \multicolumn{3}{|c|}{ Part A (randomized, double blind) } & \multicolumn{5}{|c|}{ Part B (open label) } \\
\hline & \multicolumn{2}{|c|}{ Vandetanib } & \multirow[b]{2}{*}{$\begin{array}{l}\text { Total } \\
(n=81)\end{array}$} & \multicolumn{4}{|c|}{ Vandetanib } & \multirow[b]{2}{*}{$\begin{array}{l}\text { Total } \\
(n=61)\end{array}$} \\
\hline & $\begin{array}{l}150 \mathrm{mg} \\
(n=40)\end{array}$ & $\begin{array}{l}300 \mathrm{mg} \\
(n=41)\end{array}$ & & $\begin{array}{l}100 \mathrm{mg} \\
(n=5)\end{array}$ & $\begin{array}{c}150 \mathrm{mg} \\
(n=9)\end{array}$ & $\begin{array}{c}200 \mathrm{mg} \\
(n=8)\end{array}$ & $\begin{array}{l}300 \mathrm{mg} \\
(n=39)\end{array}$ & \\
\hline Any $A E$ & 39 (97.5) & $40(97.6)$ & 79 (97.5) & $5(100)$ & $7(77.8)$ & $8(100)$ & $34(87.2)$ & $54(88.5)$ \\
\hline Diarrhea & 15 (37.5) & $18(43.9)$ & $33(40.7)$ & $1(20.0)$ & $2(22.2)$ & $3(37.5)$ & 7 (17.9) & $13(21.3)$ \\
\hline Rash & $8(20.0)$ & $13(31.7)$ & $21(25.9)$ & 0 & 0 & $1(12.5)$ & $5(12.8)$ & $6(9.8)$ \\
\hline $\begin{array}{l}\text { Blood thyroid-stimulating } \\
\text { hormone increased }\end{array}$ & $11(27.5)$ & $9(22.0)$ & $20(24.7)$ & 0 & 0 & $1(12.5)$ & $5(12.8)$ & $6(9.8)$ \\
\hline Hypocalcemia & $8(20.0)$ & $12(29.3)$ & $20(24.7)$ & $2(40.0)$ & 0 & $1(12.5)$ & $9(23.1)$ & $12(19.7)$ \\
\hline ECG QT prolonged & $5(12.5)$ & $14(34.1)$ & 19 (23.5) & $1(20.0)$ & 0 & $2(25.0)$ & $7(17.9)$ & $10(16.4)$ \\
\hline Hypertension & $8(20.0)$ & $11(26.8)$ & 19 (23.5) & $1(20.0)$ & $1(11.1)$ & 0 & $6(15.4)$ & $8(13.1)$ \\
\hline Keratopathy & $5(12.5)$ & $13(31.7)$ & $18(22.2)$ & $2(40.0)$ & $2(22.2)$ & 0 & $6(15.4)$ & $10(16.4)$ \\
\hline Fatigue & $8(20.0)$ & $7(17.1)$ & 15 (18.5) & & & & & \\
\hline $\begin{array}{l}\text { Alanine aminotransferase } \\
\text { increased }\end{array}$ & $5(12.5)$ & $7(17.1)$ & $12(14.8)$ & 0 & $1(11.1)$ & 0 & $6(15.4)$ & $7(11.5)$ \\
\hline Dermatitis acneiform & $6(15.0)$ & $6(14.6)$ & $12(14.8)$ & $1(20.0)$ & 0 & 0 & $2(5.1)$ & $3(4.9)$ \\
\hline Asthenia & $5(12.5)$ & $6(14.6)$ & 11 (13.6) & $1(20.0)$ & $1(11.1)$ & 0 & $9(23.1)$ & $11(18.0)$ \\
\hline Hypomagnesemia & $4(10.0)$ & $7(17.1)$ & $11(13.6)$ & $2(40.0)$ & 0 & $1(12.5)$ & $5(12.8)$ & $8(13.1)$ \\
\hline $\begin{array}{l}\text { Aspartate aminotransferase } \\
\text { increased }\end{array}$ & $3(7.5)$ & $6(14.6)$ & $9(11.1)$ & $1(20.0)$ & 0 & 0 & $6(15.4)$ & $7(11.5)$ \\
\hline Decreased appetite & $2(5.0)$ & $7(17.1)$ & $9(11.1)$ & $1(20.0)$ & $1(11.1)$ & $1(12.5)$ & $1(2.6)$ & $4(6.6)$ \\
\hline Hypokalemia & $2(5.0)$ & $7(17.1)$ & $9(11.1)$ & $2(40.0)$ & $1(11.1)$ & $1(12.5)$ & $6(15.4)$ & $10(16.4)$ \\
\hline
\end{tabular}

$\mathrm{AE}$, adverse event; ECG, electrocardiogram. 
Table 5 Summary of QT/QTCF intervals for Part A (randomized, double-blind phase) and Part B (open-label phase): safety population.

\begin{tabular}{|c|c|c|c|c|c|c|c|c|}
\hline \multirow[b]{3}{*}{ Patients, $\boldsymbol{n}(\%)$} & \multicolumn{3}{|c|}{ Part A* (randomized, double blind) } & \multicolumn{5}{|c|}{ Part $\mathbf{B}^{\dagger}$ (open label) } \\
\hline & \multicolumn{2}{|c|}{ Vandetanib } & \multirow[b]{2}{*}{$\begin{array}{l}\text { Total } \\
(n=81)\end{array}$} & \multicolumn{4}{|c|}{ Vandetanib } & \multirow[b]{2}{*}{$\begin{array}{c}\text { Total } \\
(n=61)\end{array}$} \\
\hline & $\begin{array}{l}150 \mathrm{mg} \\
(n=40)\end{array}$ & $\begin{array}{l}300 \mathrm{mg} \\
(n=41)\end{array}$ & & $\begin{array}{l}100 \mathrm{mg} \\
(n=5)\end{array}$ & $\begin{array}{c}150 \mathrm{mg} \\
(n=9)\end{array}$ & $\begin{array}{c}200 \mathrm{mg} \\
(n=8)\end{array}$ & $\begin{array}{l}00 \mathrm{mg} \\
(n=39) \\
\end{array}$ & \\
\hline \multicolumn{9}{|c|}{ QTcF value at any time during treatment (ms) } \\
\hline$>500$ & $1(2.5)$ & $3(7.3)$ & $4(4.9)$ & 0 & 0 & 0 & 0 & 0 \\
\hline$\leq 500$ & $40(100)$ & $39(95.1)$ & $79(97.5)$ & $5(100)$ & $9(100)$ & $8(100)$ & $39(100)$ & $61(100)$ \\
\hline \multicolumn{9}{|c|}{ Incidence of QTcF prolongation (ms) } \\
\hline$>450$ & $16(40.0)$ & $20(48.8)$ & $36(44.4)$ & $1(20.0)$ & $4(44.4)$ & $2(25.0)$ & $18(46.2)$ & $25(41.0)$ \\
\hline$>480$ & $3(7.5)$ & $7(17.1)$ & $10(12.3)$ & 0 & 0 & 0 & $5(12.8)$ & $5(8.2)$ \\
\hline$>500$ & $1(2.5)$ & $3(7.3)$ & 4 (4.9) & 0 & 0 & 0 & 0 & 0 \\
\hline $\begin{array}{l}\text { Mean time to first } \\
\text { QTcF } \\
\text { prolongation } \\
\text { (days) }\end{array}$ & 105.2 & 82.6 & 92.6 & 244.0 & 149.5 & 210.5 & 104.4 & 125.7 \\
\hline $\begin{array}{l}\text { Mean duration of } \\
\text { QTcF } \\
\text { prolongation } \\
\text { (days) }\end{array}$ & 106.8 & 125.5 & 118.3 & 91.0 & 68.6 & 58.0 & 67.1 & 67.2 \\
\hline \multicolumn{9}{|c|}{ Number of QTcF prolongations, $n(\%)$} \\
\hline 1 & $12(30.0)$ & $9(22.0)$ & $21(25.9)$ & $1(20.0)$ & $3(33.3)$ & $1(12.5)$ & $12(30.8)$ & $17(27.9)$ \\
\hline 2 & $2(5.0)$ & $8(19.5)$ & $10(12.3)$ & 0 & $1(11.1)$ & $1(12.5)$ & $5(12.8)$ & $7(11.5)$ \\
\hline 3 & $2(5.0)$ & $2(4.9)$ & $4(4.9)$ & 0 & 0 & 0 & $1(2.6)$ & $1(1.6)$ \\
\hline 4 & 0 & $1(2.4)$ & $1(1.2)$ & 0 & 0 & 0 & 0 & 0 \\
\hline
\end{tabular}

of the patients entering the open-label phase of the study, $61 \%$ received 2 years of treatment with vandetanib and $74 \%$ completed the study (including deaths). The most common cause of discontinuation of treatment prior to completing 2 years of treatment was worsening of the patient's condition. The overall safety and tolerability of vandetanib in Part B was consistent with that observed in Part A. The most common AEs included diarrhea, hypocalcemia, asthenia, QTc prolongation, hypokalemia and keratopathy. The number and type of AEs reported during the study were consistent with what would be expected in this patient population and the current safety profile for vandetanib (Robinson et al. 2010, Wells et al. 2010, 2012). Although there were no clinically relevant differences between the safety profiles of vandetanib 150 and $300 \mathrm{mg}$, the incidence of the most common AEs was higher in general in the $300 \mathrm{mg}$ group and there were fewer patients in the $150 \mathrm{mg}$ dose cohort requiring dose reductions than the $300 \mathrm{mg}$ group. There were fewer study discontinuations due to AEs in the group treated with $150 \mathrm{mg}$ than the $300 \mathrm{mg}$ dose group. However, only 4 out of the 14 withdrawals secondary to AEs in Parts $\mathrm{A}$ and $\mathrm{B}$ were attributed to vandetanib at varying doses (300 mg $(n=2), 150 \mathrm{mg}(n=1)$ and $100 \mathrm{mg}(n=1))$.
The small number of withdrawals makes it difficult to make definitive conclusions.

Abnormalities in clinical laboratory parameters, vital signs, ECG and left ventricular ejection fraction data were consistent with the known safety profile for vandetanib. QTcF prolongations occurred sooner and more frequently in the $300 \mathrm{mg}$ group than in the $150 \mathrm{mg}$ group, and recovery time was also longer for the former. In Part B, QTcF prolongations ( $>480 \mathrm{~ms}$ ) occurred in five patients in the $300 \mathrm{mg}$ group; however, there were no QTc prolongations $>500 \mathrm{~ms}$ across any vandetanib dose groups, and no reports of torsades de pointes during the study. Ophthalmology results also showed a more favorable safety profile for the lower dose group, although abnormalities appeared to stabilize across different dose groups during Part B.

Our study showed clinical benefits at both vandetanib doses of 150 and $300 \mathrm{mg}$. The study was not powered to identify a statistically significant difference between doses, but there was an overall trend toward greater efficacy with $300 \mathrm{mg}$ vs $150 \mathrm{mg}$ as the initial dose. Physicians experienced in treating patients with advanced MTC can individualize therapy based on approved dosing strategies. The vandetanib prescribing information states that the (c) 2019 Society for Endocrinology Published by Bioscientifica Ltd. Printed in Great Britain 
recommended dose is $300 \mathrm{mg}$ once daily; this dose can be reduced to $200 \mathrm{mg}$ and then to $100 \mathrm{mg}$ if needed due to AEs (Sanofi Genzyme 2016). This strategy aims to improve tolerability, while delivering similar efficacy based on the data from the present study, and allow treatment to continue for a longer duration.

Patient tolerability and safety are important considerations in the use of this agent as therapy may be continued long term in patients who show continued response to therapy. In such patients, it is necessary to balance the therapeutic benefit (response or lack of progression of the malignancy) with annoying (diarrhea or skin rash) or unsafe (QTcF prolongation, renal dysfunction, profound hypocalcemia, or hypothyroidism unresponsive to replacement) AEs. It seems reasonable to initiate therapy at the approved dose and then to adjust the dose over time to optimize the therapeutic and $\mathrm{AE}$ profile. The prolonged half-life of vandetanib makes it possible to titrate the dose downward, if needed, using the available 100 and $300 \mathrm{mg}$ vandetanib tablets. For example, patients initially treated with vandetanib $300 \mathrm{mg} /$ day who develop unsafe or intolerable AEs and have an initial tumor response should be considered for dose reduction. Given that both vandetanib doses in this study showed clinical benefit, patients with renal dysfunction, severe hypertension, or a significantly low body mass index have the option to start with a low initial dose. Previous publications have also described AE management strategies with vandetanib (Cabanillas et al. 2011, Grande et al. 2013).

Patients in our study whose disease had progressed on the $150 \mathrm{mg}$ dose were able to enter the open-label part of the study at the increased dose of $300 \mathrm{mg}$. However, efficacy was not assessed in these patients, and further assessments will be required to determine the efficacy benefits of increasing the vandetanib dose and overcoming potential drug resistance.

To conclude, in the absence of a curative treatment for locally advanced or metastatic MTC, the availability of treatments with the ability to substantially prolong time to disease progression with limited side effects is an important clinical advance for this disease. Although the results of our study showed clinical response with both vandetanib doses, the $300 \mathrm{mg}$ dose showed a more favorable trend compared with the $150 \mathrm{mg}$ group in ORR. This indicates that, for most patients, $300 \mathrm{mg}$ vandetanib is the most appropriate starting dose; however, dose reductions to manage AEs and lower initial doses for patients with particular comorbidities can be considered.

\section{Supplementary data}

This is linked to the online version of the paper at https://doi.org/10.1530/ ERC-18-0258.

\section{Declaration of interest}

Mimi I Hu: Research support: Sanofi Genzyme; Consulting or advisory role: Blueprint Medicines, Eisai Medical Research; Speakers' bureau: Eisai Medical Research. Rossella Elisei: Consulting or advisory role: Eisai, Sanofi Genzyme, Exelixis, Loco; Speakers' bureau: Eisai, Sanofi Genzyme; Travel: Sanofi Genzyme. Marek Dedecjus: No relationship to disclose. Aron Popovtzer: No relationship to disclose. Maralyn Druce: Consulting or advisory role: Ipsen; Travel: Ipsen, Novartis. Ellen Kapiteijn: No relationship to disclose. Furio Pacini: Speakers' bureau: Sanofi Genzyme. Laura Locati: Consulting or advisory role: Eisai, BMS, Ipsen; Research funding: Eisai. Jolanta Krajewska: No relationship to disclose. Richard Weiss: Employment: Employee of Genzyme at the time of the study, now employed by Radius Health. Robert F Gagel: Stock or other ownership interest: Varian Medical Systems (VAR), Varex Imaging Corporation (VREX); Patents: holder of patent formulations of the sulfonylurea receptor in persistent hypoglycemic hyperinsulinemia of infancy (currently no commercial value).

\section{Funding}

This work was supported by Sanofi and the University of Texas MD Anderson Cancer Center (Cancer Center Support Grant CA16672).

\section{Acknowledgements}

The authors thank Richard Ogilvy-Stewart from Mudskipper Business Ltd who provided medical writing assistance funded by Sanofi Genzyme.

\section{References}

Cabanillas ME, Hu MI, Durand JB \& Busaidy NL 2011 Challenges associated with tyrosine kinase inhibitor therapy for metastatic thyroid cancer. Journal of Thyroid Research 2011 985780. (https://doi. org/10.4061/2011/985780)

Carlomagno F, Vitagliano D, Guida T, Ciardiello F, Tortora G, Vecchio G, Ryan AJ, Fontanini G, Fusco A \& Santoro M 2002 ZD6474, an orally available inhibitor of KDR tyrosine kinase activity, efficiently blocks oncogenic RET kinases. Cancer Research 62 7284-7290.

Grande E, Kreissl MC, Filetti S, Newbold K, Reinisch W, Robert C, Schlumberger M, Tolstrup LK, Zamorano JL \& Capdevila J 2013 Vandetanib in advanced medullary thyroid cancer: review of adverse event management strategies. Advances in Therapy 30 945-966. (https://doi.org/10.1007/s12325-013-0069-5)

Hundahl SA, Fleming ID, Fremgen AM \& Menck HR 1998 A National Cancer Data Base report on 53,856 cases of thyroid carcinoma treated in the U.S., 1985-1995. Cancer 83 2638-2648. (https://doi. org/10.1002/(SICI)1097-0142(19981215)83:12<2638::AIDCNCR31>3.0.CO;2-1)

Kloos RT, Eng C, Evans DB, Francis GL, Gagel RF, Gharib H, Moley JF, Pacini F, Ringel MD, Schlumberger M, et al. 2009 Medullary thyroid cancer: management guidelines of the American Thyroid Association. Thyroid 19 565-612. (https://doi.org/10.1089/ thy.2008.0403)

Martins RG, Rajendran JG, Capell P, Byrd DR \& Mankoff DA 2006 Medullary thyroid cancer: options for systemic therapy of metastatic disease? Journal of Clinical Oncology 24 1653-1655. (https://doi. org/10.1200/JCO.2005.05.4106)
2019 Society for Endocrinology Published by Bioscientifica Ltd. Printed in Great Britain 
Modigliani E, Cohen R, Campos J-M, Conte-Devolx B, Maes B, Boneu A, Schlumberger M, Bigorgne J-C, Dumontier P, Leclerc L, et al. 1998 Prognostic factors for survival and for biochemical cure in medullary thyroid carcinoma: results in 899 patients. The GETC Study Group. Groupe d'etude des tumeurs a calcitonine. Clinical Endocrinology 48 265-273. (https://doi.org/10.1046/j.1365-2265.1998.00392.x)

Robinson BG, Paz-Ares L, Krebs A, Vasselli J \& Haddad R 2010 Vandetanib $(100 \mathrm{mg})$ in patients with locally advanced or metastatic hereditary medullary thyroid cancer. Journal of Clinical Endocrinology and Metabolism 95 2664-2671. (https://doi.org/10.1210/jc.2009-2461)

Roman S, Lin R \& Sosa JA 2006 Prognosis of medullary thyroid carcinoma: demographic, clinical, and pathologic predictors of survival in 1252 cases. Cancer 107 2134-2142. (https://doi. org/10.1002/cncr.22244)

Sanofi Genzyme 2016 CAPRELSA® prescribing information.Cambridge, MA, USA: Sanofi Genzyme. (available at: http://www.caprelsa.com/ files/caprelsa-pi.pdf)

Wedge SR, Ogilvie DJ, Dukes M, Kendrew J, Chester R, Jackson JA, Boffey SJ, Valentine PJ, Curwen JO, Musgrove HL, et al. 2002
ZD6474 inhibits vascular endothelial growth factor signaling, angiogenesis, and tumor growth following oral administration. Cancer Research 62 4645-4655.

Wells SA, Gosnell JE, Gagel RF, Moley J, Pfister D, Sosa JA, Skinner M, Krebs A, Vasselli J \& Schlumberger M 2010 Vandetanib for the treatment of patients with locally advanced or metastatic hereditary medullary thyroid cancer. Journal of Clinical Oncology 28 767-772. (https://doi.org/10.1200/JCO.2009.23.6604)

Wells SA, Robinson BG, Gagel RF, Dralle H, Fagin JA, Santoro M, Baudin E, Elisei R, Jarzab B, Vasselli JR, et al. 2012 Vandetanib in patients with locally advanced or metastatic medullary thyroid cancer: a randomized, double-blind Phase III trial. Journal of Clinical Oncology 30 134-141. (https://doi.org/10.1200/ JCO.2011.35.5040)

Wells SA Jr, Asa SL, Dralle H, Elisei R, Evans DB, Gagel RF, Lee N, Machens A, Moley JF, Pacini F, et al. 2015 Revised American Thyroid Association guidelines for the management of medullary thyroid carcinoma. Thyroid 25 567-610. (https://doi.org/10.1089/ thy.2014.0335)

Received in final form 24 October 2018 Accepted 12 November 2018 (c) 2019 Society for Endocrinology Published by Bioscientifica Ltd. Printed in Great Britain 